\title{
Elemental and phase characterization of quartz samples from Meliti (Florina, Greece)
}

\author{
Georgios Charalampides", Anastasia Liana, Konstantinos Vatalis, and Nikolas-Ploutarch \\ Benetis \\ Department of Environmental Engineering, Technological Educational Institution of Western \\ Macedonia, Koila Kozani, 50131, Greece
}

\begin{abstract}
In this work, a geological, phase and elemental characterization of quartz samples, deriving from Meliti area, is presented. The bedrock of the investigated area belongs to Pelagonian Nappe (Middle Triassic - Lower Jurassic) and consists predominantly of metamorphic basement including mainly mica schists where biotite dominates in relation to muscovite. Specifically, the quartz samples investigated in this study were collected at Moutsouna (Roudina) site about 3,5 km NNW of Meliti village. SEM-EDS, ICP-MS and XRD results indicate that quartz mineral originating from Meliti area is free from other microcrystalline phases. Hence, the quartz mineral found is highly pure and can be used for production of ultra-high purity quartz for special applications, as long as the deposits are found to be exploitable.
\end{abstract}

\section{Introduction}

Quartz is the second most abundant mineral in the Earth's continental crust, after feldspar. It is found in nature in varying purities and forms. Commercially, quartz is traded in various qualities for different industrial applications. It can be used either for high added value applications such as silicon-metal wafers, optical glass or PV panels or for ordinary applications such as foundry sand for metal castings or as a filler for adhesives and grouts [13]. Quartz deposits have been found in many regions in Greece. Most important-occurrences of quartz in Greece can be found in Lavrio and Penteli (Attiki), Soufli (Thrace), Petsofas (Lesvos), Avysallos (Serifos), Ios (Cyclades) and Meliti (Florina, Western Macedonia). The latter was the region that was investigated in the present study. The occurrence of quartz in each of the aforementioned places may have different forms and colors [4-6].

\section{Geological setting}

In general, the bedrock of the investigated area (Roudina near Meliti village, close to city of Florina, Western Macedonia Region, Greece) belongs to Pelagonian Nappe (Middle Triassic - Lower Jurassic) and consists predominantly of metamorphic basement including the following: (a) Schists of various mineralogical composition. They are mainly mica schists

\footnotetext{
*Corresponding author: chara@teiwm.gr
} 
where biotite dominates in relation to muscovite (garnet schists, chlorite schists, epidote schists). Muscovite schists are also present in a smaller extent (chlorite - chloritoid schists, chlorite - garnet schists). (b) Basic metamorphic igneous rocks within the schists of the metamorphic system (region of the village Skopos) and in less extent, these igneous rocks are intercalated (amphibolites gneisses, metagabros, greenstones). (c) Orthogneisses consisting mainly of mica orthogneisses, augene gneisses and gneisses of schistone structure.

\subsection{Sampling}

Specifically, the quartz samples investigated in this study were collected at Roudina site about 3,5 km NNW of Meliti village (Figure 1) from Pleistocene aged conglomerate series consisting predominantly of various calcareous pebbles, with mainly calcitic matrix. Heavily bedded with a thickness up to some tenths of meters. The alternate with sandstones and grit and they develop in the areas of the villages Kella, Klidi and Vevi. Also the conglomerate series include sandstones, sand and red clays of river - torrential origin; the thinner elements gradually dominate towards the center of the basin. Even more, lenses of Neocene limestones and marbles are surrounding the small quartz occurrences of the Roudina site. These lenses consist of white-yellow to white-gray, compact, fossiliferous mainly limestones, marls alternating with gray-greenish, clayey marls and clays (Geological Map, Vevi sheet, IGME).

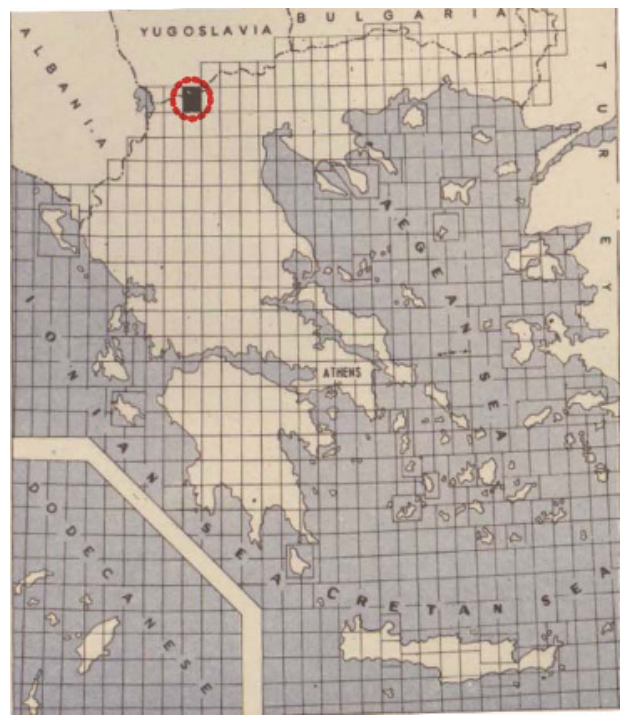

Fig. 1. The geological setting $40^{\circ} 50^{\prime} 0^{\prime \prime}$ North, $21^{\circ} 35^{\prime} 0^{\prime \prime}$ East of Meliti (Florina, Greece) in the map of Greece

The present geological survey is focused on the quartz mineral deposits observation in Roudina area. Samples from three different positions were collected. Area photographs of the sampling areas are shown in Figure 2. From these three positions, five samples were examined. Due to the non-uniformity of the terrain, more samples (three) were examined from Position 1 in order to obtain better sampling conditions of the area in this position. From the other two positions one sample per position was examined (Table 1). The quartz occurrences mainly consist of milky quartz. Quartz fractions of spheroidal shape (with a diameter up to $40 \mathrm{~cm}$ ) were found scattered over long distances covering the entire survey area. It seems that these quartz occurrences in the study area constitute mechanical secondary concentrations of weathering and transportation of a pre-existing deposit. They might have been created mainly by the transposition, sorting and deposition process of clastic weathering 
products. Generally, these alluvial (fluvial) quartz concentrations could be an important source of secondary mechanical deposits.
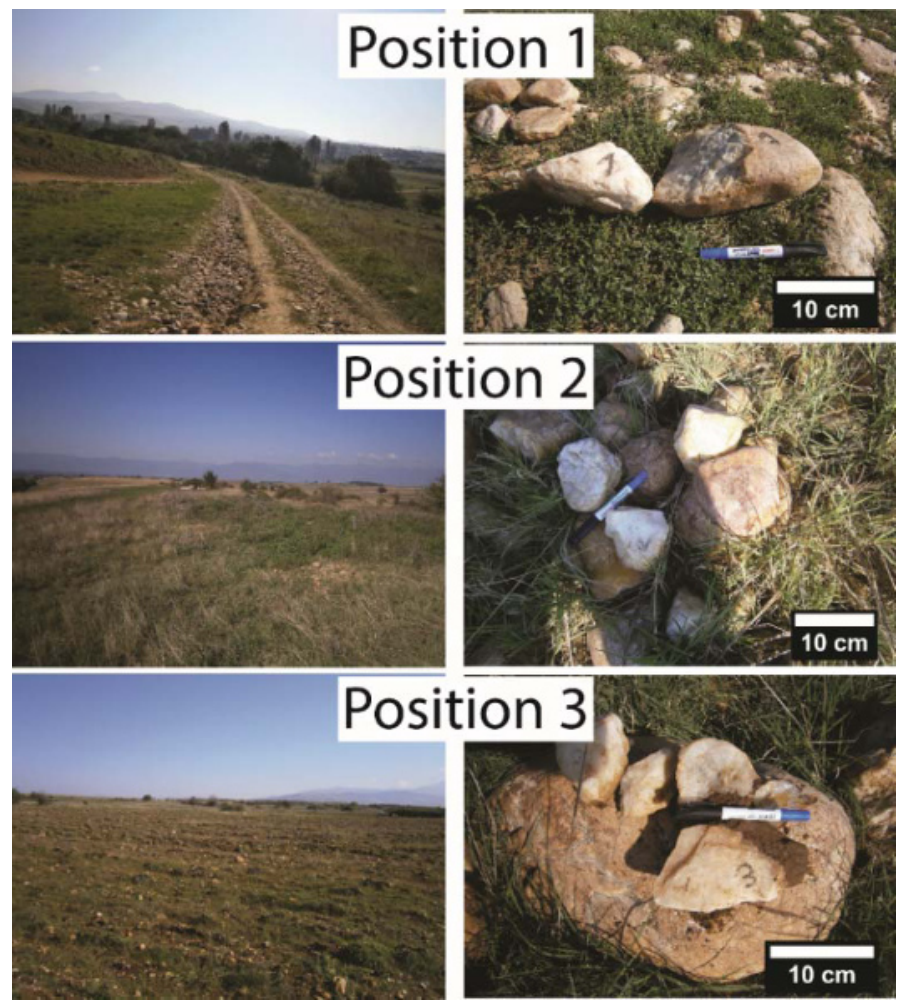

Fig. 2. The three sampling positions in the setting of Roudina (Meliti, Florina).

\section{Characterization Techniques}

X-Ray Diffraction (XRD) was carried out in order to identify the mineralogical phases which are present in the quartz samples. Prior to the XRD measurements, the quartz samples were mechanically crushed and sieved through a $45 \mu \mathrm{m}$ stainless steel sieve in order to obtain fine powder. XRD analysis was performed, using a 3003 TT Rich. Seifert Diffractometer (Ni filtered, with $\mathrm{Cu} \mathrm{Ka}$ irradiation, $\lambda=0.154 \mathrm{~nm}$ ). The $2 \theta$ scan range varied from $5^{\circ}$ to $80^{\circ}$. Phase identification and quantification was performed by matching the acquired XRD spectra with the COD-AMCSD database. The phase identification and the XRD measurement procedure includes an instrumental error of approximately $2 \% \mathrm{wt}$, regarding the phase composition.

Morphological examination was conducted by means of Scanning Electron Microscopy (SEM), using a JEOL 6610LV. The elemental analysis, by means of Energy Dispersive Spectroscopy (EDS), was carried out using an X-Max 80 (Oxford Instruments) detector attached to the SEM. Images, elements maps and spectra were acquired and analysed using AZtech Nanoanalysis software. Prior to SEM observation the samples were coated with carbon in order to eliminate charging under the electron beam.

Trace-element analysis was carried out by inductively coupled plasma mass spectrometry (ICP-MS). A Perkin Elmer ELAN 6100 ICP-MS device was used for the trace-element detection in the quartz samples. The standard deviation of the SEM-EDS and ICP-MS measurements was calculated via the manufacturer's software. 
Table 1. Sampling positions and sample names.

\begin{tabular}{|c|c|}
\hline Position & Sample Name \\
\hline \multirow{2}{*}{1} & Q1 \\
\cline { 2 - 2 } & Q2 \\
\cline { 2 - 2 } & Q3 \\
\hline 2 & Q4 \\
\hline 3 & Q5 \\
\hline
\end{tabular}

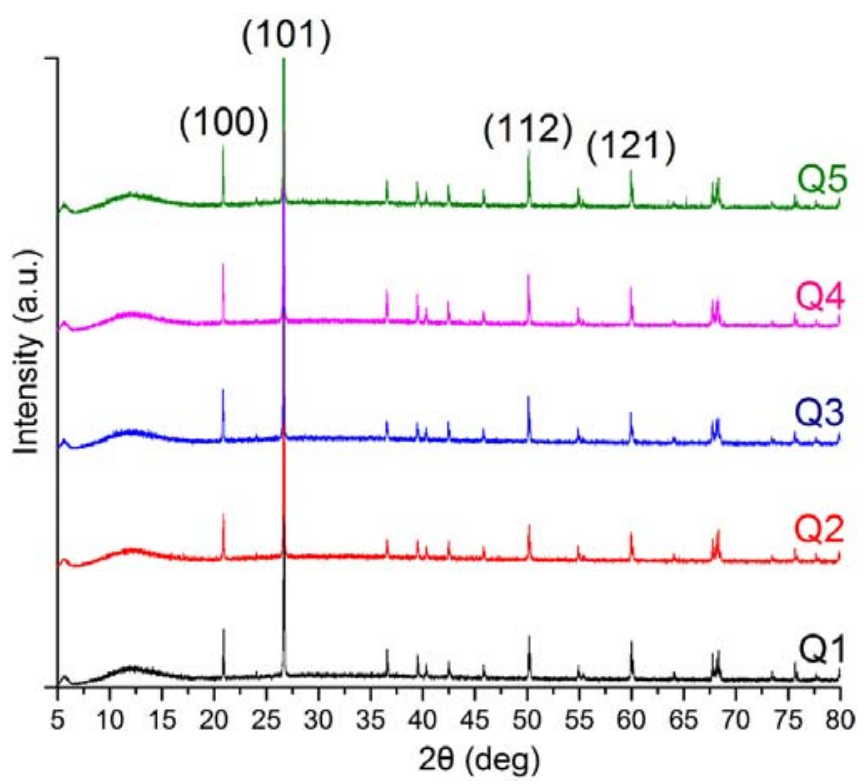

Fig. 3. XRD patterns of the five samples examined in this study. It is obvious from these patterns that, except pure quartz, no other accessory microcrystalline phases were detected in the samples.

\section{Results and Discussion}

The XRD results are given in Figure 3. The XRD patterns of all samples exhibited only the distinct peaks that correspond solely to quartz. Specifically, the peaks at $20.9^{\circ}, 26.6^{\circ}, 50.1^{\circ}$ and $59.95^{\circ} 2 \theta$ correspond to the crystallographic planes (100), (101), (112) and (121) of the mineralogical phase of quartz. Moreover, SEM-EDS analysis was performed in order to gain insights into the main elements of the investigated mineral samples. In Figure 4, indicative SEM-EDS results of the Q1 sample are shown. As it is shown form Figure 4, the EDS spectrum denotes the presence of only $\mathrm{Si}(52.2 \% \mathrm{wt})$ and $\mathrm{O}(47.8 \mathrm{wt} \%)$. A Si:O ratio $1: 2$ is calculated by converting the \%wt compositions of the elements into atomic composition (at \%) of the oxide $\left(\mathrm{SiO}_{2}\right)$. Furthermore, on the right side of Figure 4 an elemental map of $\mathrm{Si}$ and $\mathrm{O}$ is shown. Si and $\mathrm{O}$ appear to be evenly distributed on the surface of the sample, which indicates the absence of other major elements or impurities. Rather similar spectra and elemental maps were obtained from the rest of the samples examined. 


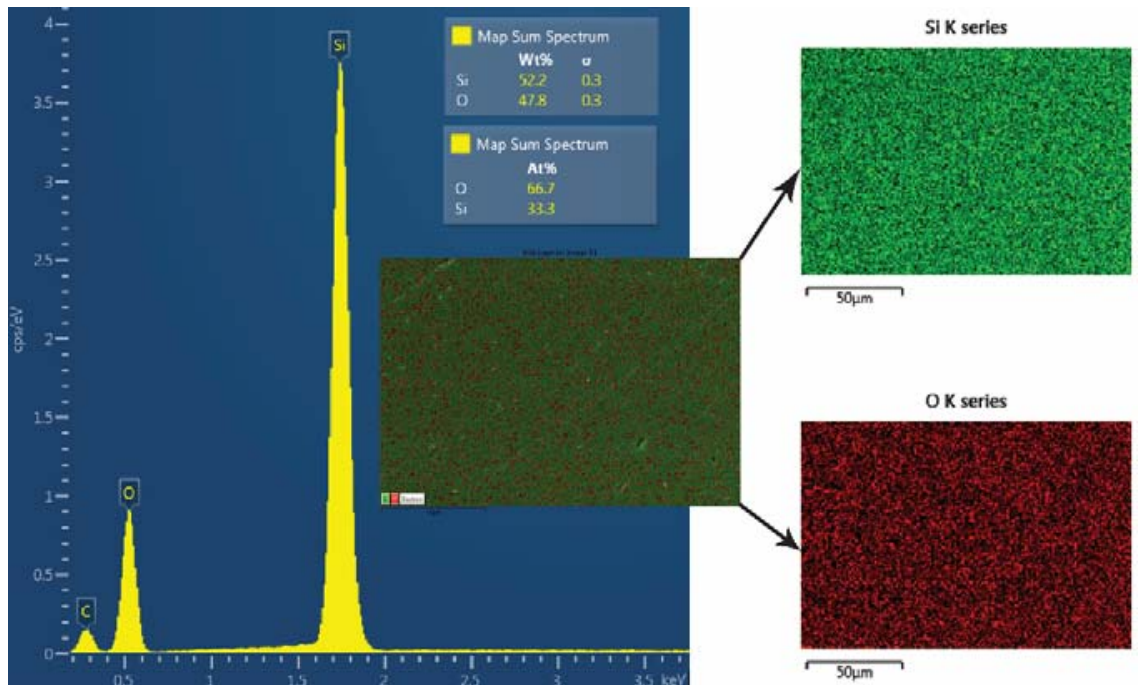

Fig. 4. SEM-EDS analysis and elemental mapping of the main chemical elements $\mathrm{Si}$ and $\mathrm{O}$ of the quartz sample (Q1) taken from position 1.

Nevertheless, the ICP-MS trace element analysis (Table 3) revealed the presence of five trace-elements ( $\mathrm{Li}, \mathrm{Na}, \mathrm{Al}, \mathrm{K}, \mathrm{Fe})$ in the quartz samples examined. The Q5 sample, deriving from position 3, exhibited the higher trace-element concentrations. Loss of Ignition (\%LOI) results for all samples was quite low (lower than $0.2 \%$ ) as expected for quartz mineral. Our analyses results are in good agreement with the literature findings $[7,8]$.

Table 2. EDS results for all samples investigated. The standard deviation is indicated with \pm .

\begin{tabular}{|c|c|c|c|c|}
\hline \multirow{2}{*}{ Sample Name } & \multicolumn{2}{|c|}{ \% wt elemental composition } & \multicolumn{2}{c|}{ \% wt elemental composition } \\
\cline { 2 - 5 } & $\mathbf{S i}$ & $\mathbf{O}$ & $\mathbf{S i}$ & $\mathbf{O}$ \\
\hline Q1 & $52.2 \pm 0.3$ & $47.8 \pm 0.3$ & $33.3 \pm 0.3$ & $66.7 \pm 0.3$ \\
\hline Q2 & $51.7 \pm 0.3$ & $48.3 \pm 0.3$ & $33.3 \pm 0.3$ & $66.7 \pm 0.3$ \\
\hline Q3 & $51.7 \pm 0.5$ & $48.3 \pm 0.5$ & $33.3 \pm 0.5$ & $66.7 \pm 0.5$ \\
\hline Q4 & $52.1 \pm 0.4$ & $47.9 \pm 0.4$ & $33.3 \pm 0.4$ & $66.7 \pm 0.4$ \\
\hline Q5 & $50.3 \pm 0.4$ & $49.7 \pm 0.4$ & $33.3 \pm 0.4$ & $66.7 \pm 0.4$ \\
\hline
\end{tabular}

Table 3. ICP-MS trace-element analysis and Loss on Ignition (\%LOI) results.

\begin{tabular}{|c|c|c|c|c|c|c|}
\hline \multirow{2}{*}{ Sample Name } & \multicolumn{5}{|c|}{$\mathbf{~ m g / k g ~ ( p p m ) ~}$} & \multirow{2}{*}{ \%LOI } \\
\cline { 2 - 6 } & $\mathbf{L i}$ & $\mathbf{N a}$ & $\mathbf{A l}$ & $\mathbf{K}$ & $\mathbf{F e}$ & \\
\hline Q1 & $<0.50 \pm 0.01$ & $44 \pm 0.88$ & $245 \pm 4.9$ & $18 \pm 0.40$ & $430 \pm 8.6$ & 0.10 \\
\hline Q2 & $<0.50 \pm 0.01$ & $47 \pm 0.94$ & $135 \pm 2.7$ & $<10 \pm 0.20$ & $165 \pm 3.3$ & 0.15 \\
\hline Q3 & $1.80 \pm 0.04$ & $25 \pm 0.50$ & $135 \pm 2.7$ & $<10 \pm 0.20$ & $70 \pm 1.4$ & 0.13 \\
\hline Q4 & $0.50 \pm 0.01$ & $<20 \pm 0.40$ & $135 \pm 2.7$ & $23 \pm 0.46$ & $215 \pm 4.3$ & 0.07 \\
\hline Q5 & $1.6 \pm 0.03$ & $<20 \pm 0.40$ & $7700 \pm 154$ & $550 \pm 11$ & $530 \pm 10.6$ & 0.04 \\
\hline
\end{tabular}




\section{Conclusions}

In this work quartz samples originating from Meliti area (Florina, Greece) were analyzed. According to the XRD analysis the quartz mineral originating is free from other major or even accessory microcrystalline mineral phases. According to semi-quantitative chemical analysis (SEM-EDS) the major elements detected in the samples were only $\mathrm{Si}$ and $\mathrm{O}$ in the ratio 1:2 $\left(\mathrm{SiO}_{2}\right)$. On the other hand, trace-element analysis, carried out by means of ICP-MS indicated the presence of several trace elements in the quartz interstitial crystal sites. Consequently, the quartz mineral found in the investigated area is undoubtedly very pure and therefore this could be used for the production of ultra-high purity quartz, as long as the deposits are found to be exploitable.

The authors would like to thank the Specific-Account Research Committee (ELKE) of TEI of Western Macedonia for financing the research work presented here under the research grant 80161 Moreover, the contribution of Apostolos Baklavaridis (Materials Science Engineer, PhD) to the SEM-EDS and $\mathrm{XRD}$ analyses is gratefully acknowledged.

\section{References}

1. S. Platias, K.I. Vatalis, and G. Charalampides, Procedia Econ. Financ. 14, 491 (2014)

2. K.I. Vatalis, G. Charalambides, and N.P. Benetis, Procedia Econ. Financ. 24, 734 (2015)

3. K.I. Vatalis, G. Charalampides, S. Platias, N.P. Benetis, Procedia Econ. Financ. 14, 624 (2014)

4. T. A., The mineral wealth of Greece (In Greek) (Giachoudis Publications, Thessaloniki, 2005)

5. N. Arvanitidis, S. Kilias, Vein Quartz Deposits of Northern Greece - Exploitable Resources for Industrial Uses, Mineral Deposits (Balkema, Rotterdam, 1997)

6. N. Arvanitidis, J. Geochem. Explor. 62, 217 (1998)

7. A.H. Damman, S.M. Kars, J.L.R. Touret, E.C. Rieffe, J. Kramer, R.D. Vis, I. Pintea, Eur. J. Mineral. 8, 1081 (1996)

8. H. Naka and H. Kurayasu, ISIJ Int. 33, 1252 (1993) 